\title{
Determinação de impedância elétrica de transdutores piezelétricos sob potências elevadas
}

\section{Guilherme T. Barreto*, Francisco J. Arnold.}

\section{Resumo}

Os transdutores piezelétricos são, entre várias aplicações, usados para produzir ultrassom de potência elevada. O comportamento da impedância elétrica desses transdutores revela importantes características do mesmo voltadas para um projeto. A interação do transdutor com fatores externos modifica a impedância. Neste trabalho é investigado o comportamento da impedância em relação a amplitude da tensão excitadora. Um aparato experimental foi desenvolvido para determinar a impedância dos transdutores. Foram usadas duas frequências fixas próximas a ressonância e anti-ressonância para se medir as impedâncias. Os resultados mostram pequenas variações de impedância numa faixa de tensões elétricas entre 30 e $150 \mathrm{~V}$. Outros experimentos ainda serão realizados para uma melhor depuração dos resultados obtidos neste trabalho.

\section{Palavras-chave:}

Ultrassom, ressonância, anti-ressonância

\section{Introdução}

Os transdutores piezelétricos são empregados em aplicações de conversão de eletricidade em pressão, como na produção de ultrassom. Esses transdutores são usados nas áreas médica, militar e industrial.

A curva de impedância elétrica de um transdutor piezelétrico apresenta características que definem suas condições de operação. Particularmente, permite a identificação das frequências de ressonância e antiressonância. Os valores dessas frequências podem ser alterados pela atuação de agentes e campos externos ${ }^{1}$.

Os transdutores piezelétricos usados na produção de ultrassom de potências elevadas são alimentados eletricamente por amplificadores eletrônicos de alto rendimento, como os de classe $\mathrm{D}^{2}$. Esse tipo de amplificação gera um rendimento de $95 \%$ da potência utilizada para alimentar o amplificador.

O objetivo deste trabalho é determinar os valores de impedância elétrica de um transdutor piezelétrico sob altas potências (alimentados com tensões de até 200V). $\mathrm{O}$ transdutor foi acionado por um amplificador classe $\mathrm{D}$, baseado em MOSFETs. Os valores de frequência do sinal fornecido pelo amplificador são controlados pelo oscilador IRS2453D.

\section{Resultados e Discussão}

A Figura 1 mostra o circuito do piezelétrico ligado a ponte de MOSFETS (S1-S4). A tensão HVcc alimenta o piezelétrico $\mathrm{P} 1$.

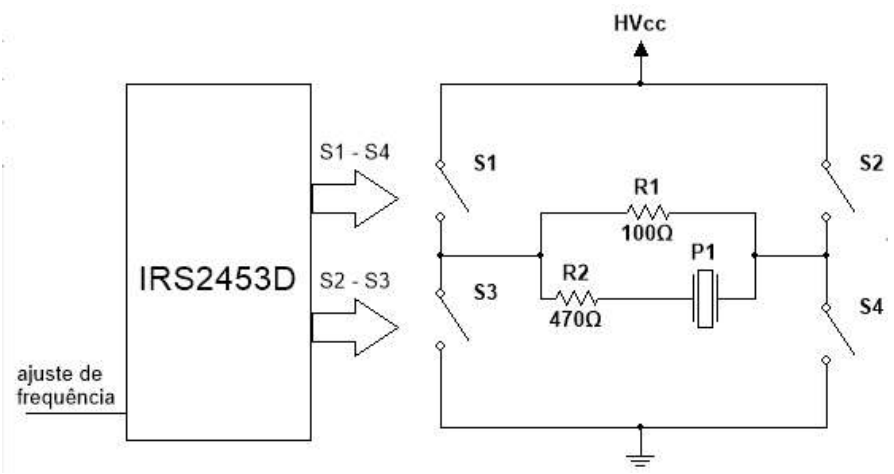

Figura 1. Circuito do piezelétrico ligado a ponte de MOSFETS.
Experiências preliminares mostraram que a configuração de ponte de MOSFETS apresentava alto ruido em sua saída a medida em que a resistência de carga aumentava. Isto foi corrigido adicionando-se o resistor R1 em paralelo com R2 e a carga piezelétrica (transdutor comercial, com frequência de $27 \mathrm{kHz}$, fabricado pela Eleceram Co. Taiwan).

Foram medidos os valores das tensões entre os terminais dos resistores R1 e R2 com valores de HVcc de $37 \mathrm{~V}, 74 \mathrm{~V}, 110 \mathrm{~V}$ e $148 \mathrm{~V}$. Assim, por meio de cálculos básicos da teoria de circuitos elétricos foram determinadas as impedâncias nas frequências de $26,8 \mathrm{kHz}$ (ressonância) e 28,4kHz (anti-ressonância). Essas frequências foram mantidas em todas as tensões usadas.

A Tabela 1 mostra os valores do módulo da impedância nas frequências de ressonância e anti-ressonância para os valores de HVcc.

Tabela 1. Módulo da impedância nas frequências de ressonância e anti-ressonância.

\begin{tabular}{|c|c|c|}
\hline Hvcc $(\mathrm{V})$ & $|\mathrm{Z}|$ ressonância $(\Omega)$ & $|\mathrm{Z}|$ anti-ressonância $(\Omega)$ \\
\hline 37 & 310,12 & 764,63 \\
\hline 74 & 337,76 & 780,34 \\
\hline 110 & 338,77 & 784,16 \\
\hline 148 & 333,00 & 791,33 \\
\hline
\end{tabular}

\section{Conclusão}

Nota-se que o aumento da impedância com a tensão aplicada em frequência fixa indica que a curva de impedância do transdutor é deslocada em relação àquela obtida sob potências menores. Outros experimentos ainda serão realizados visando um melhor conhecimento dos deslocamentos de ressonância.

${ }^{1}$ Ural, S. O.; Tuncdemir, S. Zhuang, Y.; Uchino, K. Jap. J. Appl. Phys. 2009, 48, 056509.

${ }^{2}$ Agbossou, K; Dion, J. L.; Carignan, S.; Abdelkrin, M.; Cheriti, A. IEEE Trans. on Ultrason, Ferroelect. and Freq. Ctrl. 2000, 47(4), 1036. 